\title{
CORRUPCIÓN EN EL ÁMBITO POLICIAL: SIGNIFICADOS CONSTRUIDOS POR POLICÍAS PREVENTIVOS DE TRES CIUDADES DE MÉXICO
}

\author{
Hugo Alberto Yam Chalé y Erika Nayeli Clairgue Caizero \\ Universidad Iberoamericana \\ México
}

\begin{abstract}
RESUMEN
El objetivo de este estudio fue identificar los significados construidos por policías preventivos de tres ciudades de México en torno a la corrupción en el ámbito policial y sus efectos. Se hizo un estudio de tipo fenomenológico; se recolectaron datos mediante grupos focales con policías de Tijuana y de Ciudad de México, así como de entrevistas semiestructuradas a policías de Mérida. Los relatos de los policías muestran que la corrupción ocurre en dos ámbitos: 1) en la corporación policial, debido al influyentismo y a arrestos disciplinares arbitrarios, y 2) en la interacción policía-ciudadanía, debido a la normalización, la racionalización y los bajos salarios. Algunos efectos de la corrupción son la insuficiencia de personal, equipamiento deficiente y problemas económicos. Los significados de los policías en torno a la corrupción favorecen al mantenimiento de esta práctica, siendo importante comprenderlos para así deconstruirlos y favorecer a su disminución.
\end{abstract}

Palabras Clave:

policías, corrupción policial, construccionismo social, policía mexicana

\section{CORRUPTION IN THE POLICE FIELD: MEANINGS CONSTRUCTED BY PREVENTIVE POLICE FROM THREE CITIES IN MEXICO}

\begin{abstract}
This study aimed to identify meanings constructed by preventive police officers from three cities of Mexico regarding corruption in the police and its effects. A phenomenological study was conducted; data were collected through focus groups with police officers from Tijuana and Mexico City, as well as semi-structured interviews with police officers in Mérida. The stories constructed by the police officers show that corruption occurs in two areas: (1) in the police corporation, due to influyentismo and arbitrary disciplinary arrests; and (2) in the police-citizenship interaction, due to normalization, rationalization, and low wages. Some effects of corruption are insufficient staff, poor equipment, and economic problems. The meanings constructed by the police around corruption favor the maintenance of this practice, it is important to understand them to deconstruct them and ease their reduction.
\end{abstract}

\section{Keywords:}

law enforcement, police corruption, social constructionism, mexican police, police officers

Bitácora del Artículo:

| Recibido: 10 de Julio de 2019 | Aceptado: 11 de Noviembre de 2019 | Publicado en línea: Enero - Junio de 2020 | 


\title{
CORRUPCIÓN EN EL ÁMBITO POLICIAL: SIGNIFICADOS CONSTRUIDOS POR POLICÍAS PREVENTIVOS DE TRES CIUDADES DE MÉXICO
}

\author{
Hugo Alberto Yam Chalé y Erika Nayeli Clairgue Caizero \\ Universidad Iberoamericana \\ México
}

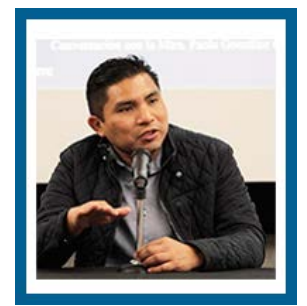

Hugo Alberto Yam Chalé Universidad Iberoamericana Ciudad de México-Tijuana Correo: hugo.yam@ibero.mx

Doctor en Psicología por la UNAM. Maestro en Psicología Aplicada al Área Criminológicay licenciado en Psicología por la Universidad Autónoma de Yucatán. Es Miembro del Sistema Nacional de Investigadores (SNI), con el nivel de Candidato. Es Profesor de tiempo completo en la Universidad Iberoamericana.

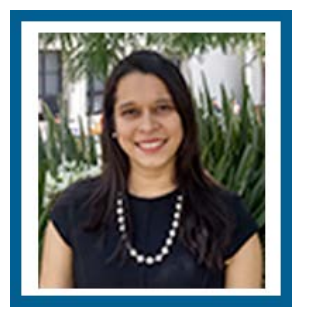

Erika Nayeli Clairgue Caizero Universidad Iberoamericana Ciudad de México-Tijuana

Correo: erika.clairgue@tijuana.ibero.mx

Maestra en estudios culturales por el Colegio de la Frontera Norte y licenciada en Psicología por la Universidad Veracruzana. Académica de tiempo completo y gestora de Vinculación Universitaria en el área de Innovación Bienestar de la Universidad Iberoamericana Ciudad de México-Tijuana, en Tijuana.

\section{CONTRIBUCIÓN DE LOS AUtORES}

Hugo Alberto Yam Chalé estuvo a cargo de la revisión de literatura, coordinación de grupos focales y transcripción de información, la realización de entrevistas, análisis de datos y redacción de resultados, discusión y conclusiones. | Erika Nayeli Clairgue Caizero participo en la revisión de literatura, coordinación de grupos focales y transcripción de información., análisis de datos y redacción de resultados, discusión y conclusiones

\section{AGRADECIMIENTOS}

Agradecemos a los policías de la Ciudad de México; Mérida, Yucatán y Tijuana, Baja California por su apoyo para la realización de este trabajo. Asimismo agradecemos la colaboración de las estudiantes de la Universidad lberoamericana Ciudad de México-Tijuana Carla Celeste Ulloa Vázquez, Rubi Silem Vazquez Meneses y Alexis Akerlundh Oviedo, por su colaboración en la realización de los grupos focales y la transcripción de las narrativas.

\section{DATOS DE Filiación de lOS Autores}

Universidad Iberoamericana Ciudad de México-Tijuana

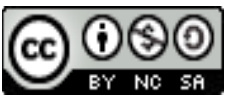

Copyright: (c) 2020 Yam-Chalé, H. A. y Clairgue, E. N.Caizero

Este es un artículo de acceso abierto distribuido bajo los términos de la licencia Creative Commons Reconocimiento-NoComercial 4.0 Internacional, por lo que su contenido gráfico y escrito se puede compartir, copiar y redistribuir total o parcialmente sin necesidad de permiso expreso de sus autoras con la única condición de que no se puede usar con fines directamente comerciales y los términos legales de cualquier trabajo derivado deben ser los mismos que se expresan en la presente declaración. La única condición es que se cite la fuente con referencia a la Revista Digital Internacional de Psicología y Ciencia Social y a sus autoras. 


\section{TABLA DE CONTENIDO}

MÉTODO

Participantes, 265

Materiales, 265

Procedimiento, 265

\section{ANÁLISIS}

\section{RESULTADOS}

Factores que favorecen a la corrupción, 266

Efectos de la corrupción, 267

Discusión

CONCLUSIONES

REFERENCIAS 


\section{$\mathbf{L}$} a corrupción es un fenómeno social complejo cuya definición depende de ámbitos y contextos específicos. Para materializarse son necesarios dos componentes: el que corrompe y el que se deja corromper; los funcionarios públicos son quienes obtienen beneficios por medio de actos de corrupción, en complicidad con personas u organizaciones, lo cual favorece la impunidad, y por tanto altera el orden público (Hernández, 2017). Así, los datos que se tienen muestran que la población mexicana percibe un alto índice de corrupción en México. Según el Índice de Percepciones sobre Corrupción (Transparency International, 2018), este país tiene un alto nivel de corrupción porque presenta un índice de 28 , siendo cero "altamente corrupto" y 100 "muy transparente".

En México la corrupción se entiende sobre todo como soborno y se vincula principalmente a la institución policial (Grijalva y Fernández, 2017). Según el INEGI (2018), durante 2017 se estiman, a nivel nacional, 1,688 actos de corrupción por cada mil elementos de policía del orden federal, estatal y municipal; de ellos 1,391 corresponden a soborno por ciudadanos, 292 a extorsiones por compañeros o superiores y cinco a personal de la corporación, sea para ingresar o para conseguir un ascenso. Es necesario indicar que el acceso a las ganancias de la corrupción no es igual para todos los policías; depende de las oportunidades derivadas de las características demográficas, sociales, económicas, culturales y delictivas, entre otras, del área donde desempeñan sus funciones (López, 2007), de ahí que los actos de corrupción se presenten en diferentes modalidades.

Según Newburn (1999), en el ámbito policial el término corrupción hace referencia a actividades como soborno, violencia y brutalidad, fabricación y destrucción de evidencia, racismo, favoritismo y nepotismo, así como a otras actividades relacionadas. Autores como Punch, Roebuck, Barker, Carter, Sayed y Bruce (citados en Newburn, 1999) sugieren nueve tipos de corrupción policial.

(1) Corrupción de autoridad: aceptación de ganancias materiales por su posición como policía; (2) Kickbacks, recibir compensaciones de bienes y servicios por asuntos relacionados a individuos particulares o compañías; (3) robo oportunista, durante detenciones o a ciudadanos fallecidos; (4) omisión o persecución por dádivas, de arrestos, crímenes, incautación de propiedades; (5) protección de criminales, para que continúen con el desarrollo de sus actividades criminales; (6) "la fija", socavar investigaciones criminales o la "pérdida" de multas de tránsito; (7) actividades criminales directas, cometer un crimen en contra de otros por ganancia personal; (8) pagos internos, para obtener roles, ascensos; (9) plantación de evidencias, principalmente en casos de drogas.

López (2007) clasifica los actos de corrupción en dos categorías generales: 1) los actos que van en contra del sistema normativo, que permiten la obtención de beneficios negros, y 2) los actos que representan una ganancia personal, que permiten obtener beneficios blancos. Los beneficios negros se relacionan con actos que atentan contra el servicio público al que están obligados los policías; aquí se incluye la corrupción ocasional mediante la cual se obtiene dinero extra en un momento determinado, como cuando se intimida a cualquier persona considerada "sospechosa" con el pretexto de estar transgrediendo algún reglamento, aunque no es clara la falta cometida. Por lo regular, en estos casos el ciudadano ofrece dinero (soborna) para no ser sancionado; esto disminuye la carga moral negativa del hecho. En otros casos, cuando la persona transgrede reglamentos o leyes se practica la extorsión, es decir, el policía solicita el dinero. En su vertiente sistemática se obtienen pagos de manera regular para no ejercer la ley contra individuos que la violan de manera cotidiana.

Por su parte, los beneficios blancos son los que se obtienen de comerciantes formales e informales (como comida, agua, refrescos, cigarros y tortas, entre otros, que son consumidos sin pagar por ellos). Pueden ser ocasionales o regularizados por medio de cuotas diarias. Son entregados en forma de propina o de recompensa por la labor del policía. Cuando son regularizados, las personas esperan que los policías actúen de manera parcial y rápida en caso de algún riesgo. En general, para la mayoría de los policías los beneficios blancos no corresponden con actos de corrupción porque consideran que son una forma en que la población reconoce y recompensa su labor como policías; esto a pesar de que las normatividades les prohíben la aceptación de bienes o de dinero (López, 2007).

Los índices de la corrupción son difíciles de medir por la falta de acceso a información confiable y de fuentes de datos únicos y comparables de modo internacional; por lo regular, incluso los datos que las investigaciones utilizan para reportar niveles de corrupción se basan en encuestas recolectadas en hogares referentes a percepciones y experiencias (Asch, Fu y Burger, 2011). Grijalva y Fernández (2017) analizaron los efectos de la percepción de corrupción en una muestra de la comunidad de la Universidad Nacional Autónoma de México. Indican que la población que percibe corrupta a la 
policía también la percibe como ineficiente y carente de compromiso con la comunidad, lo que favorece el incremento de los niveles de temor a ser víctima del delito. Esto se agrava en los casos en que hay violencia por parte de los oficiales. Silva (2016) indica que el abuso de la fuerza por parte de los policías es una de las formas de victimización relacionadas con la corrupción; comenta también que este tema ha sido poco estudiado a pesar de ser relevante porque muestra la heterogeneidad del fenómeno de las agresiones por parte de los policías y los efectos que la corrupción llega a tener.

Por otro lado, Orces (2017) indica que la corrupción afecta de manera particular a los sectores de la población menos favorecidas económicamente, siendo que en países ricos sus habitantes tienen menos probabilidad de ser víctimas de corrupción policial, mientras que la probabilidad en países pobres es significativamente alta para el ciudadano promedio. Esto es posible debido a los múltiples contactos sociales, permeados por el contexto sociocultural, entre ciudadanía y oficiales de policía. Alvarado y Silva (2011) comentan que la relación entre policías y ciudadanía implica una amplia diversidad de contactos, propósitos y espacios, favoreciendo a que se ignore lo que el policía hace en la mayoría de ellos. Estos investigadores indican que en seis de cada 10 encuentros con policías debido a faltas de tránsito, acusaciones de delitos y faltas administrativas se solicitó "mordida", y que estos actos de corrupción se agravan cuando los superiores e instancias de control participan en dichos actos. En un estudio de corrupción en la policía de tránsito de Colombia, Fink y Boehm (2011) identificaron, en una muestra de taxistas de Bogotá y Barranquilla, que el soborno era una práctica cotidiana para evitar infracciones, con conocimiento incluso de los mandos oficiales superiores.

En definitiva, la corrupción es una problemática social que genera diversidad de efectos individuales, familiares, organizacionales y sociales que, de no ser atendidos, pueden agravarse y afectar a un mayor número de personas. Intervenir en esta problemática requiere conocer este aspecto desde diferentes perspectivas; sin embargo, encontramos que la mayoría de los estudios relacionados con la corrupción se enfocan en la manera en que los ciudadanos experimentan o perciben este fenómeno social o refieren índices de corrupción. Conocer y comprender la corrupción desde la perspectiva de los actores implicados, en este caso los policías, puede favorecer a la generación de propuestas de prevención e intervención que respondan a la realidad particular en que se presenta dicha problemática. Esta es la causa de que en este estudio el interés se enfocó en los significados que los policías han establecido en torno a la co- rrupción en su ámbito laboral, así como los efectos que, desde su perspectiva, han tenido dichos actos.

Considerando que el interés de este estudio se enfoca en los significados establecidos por los policías, este análisis se desarrolló desde el construccionismo social, enfoque teórico que postula que las personas creamos la realidad conversacional en interacción con los demás, mediante las prácticas discursivas (Guanaes y Rasera, 2006), y otorga relevancia al saber compartido por una comunidad en la manutención y reproducción de la realidad (Sandoval, 2010). Aquí se sostiene que los significados los establecemos por medio de narraciones constantes y permanentes en el intercambio con los otros; además de intercambiar información, negociamos los significados que atribuimos a eventos y comportamientos, construimos identidad individual y colectiva, definimos roles y relaciones, y desarrollamos un modo específico de organizar la realidad (Perdomo, 2002).

Lo que interesa desde el construccionismo es la manera en que los sujetos narran sus experiencias y significados; lo exacto y objetivo no se logra porque al ser el conocimiento una construcción, ésta se localiza inmersa en una cultura determinada (Gergen y Warhus, 2001), de modo que la posición o posiciones que se puedan asumir frente a las diversas situaciones que se presentan, están influidas por las experiencias y significados sociales aprendidos (Donoso, 2004). Ahora bien, los significados construidos cobran importancia cuando, una vez establecidos, determinan lo que las personas hacen y lo que creen que son capaces de hacer (Valverde, 2009); dichos significados determinan cursos de acción, pero cierran otros (Ema, García y Sandoval, 2003).

Los significados construidos por los policías en torno al concepto "corrupción" pueden facilitar o dificultar su realización; incluso pueden llevar a su normalización y perpetuación. Estos actos pueden propiciar diferentes tipos de efectos, con diversos niveles de gravedad. Por ello en este estudio se pretendió dar respuesta a las preguntas “¿Cuáles son los significados que los policías preventivos de México han construido en torno a la corrupción en el ámbito policial?" y “¿Cuáles son los efectos que identifican dicha corrupción?" El objetivo que se planteó fue identificar los significados construidos por policías preventivos de tres ciudades de México en torno a la corrupción en el ámbito policial, así como los efectos que reconocen de dichos actos.

\section{MÉTodo}

La investigación se desarrolló desde un enfoque cualitativo, utilizando el método fenomenológico para conocer 
y comprender las experiencias y significados de las personas en relación con un fenómeno (Hernández-Sampieri y Mendoza, 2018). Como indica Martínez (2015), los métodos fenomenológicos estudian los fenómenos tal como son experimentados, vividos y percibidos por las personas; más que interesar la realidad externa y objetiva, interesa la manera en que es vivida y percibida por las personas. Para la recolección de datos se establecieron tres grupos focales y 21 entrevistas semiestructuradas. Los grupos focales se integraron con policías preventivos de Ciudad de México y de Tijuana, Baja California. Las entrevistas se hicieron a policías preventivos estatales de Yucatán asignados a la ciudad de Mérida.

\section{Participantes}

El muestreo fue por oportunidad, teniendo como criterio de inclusión ser o haber sido policía preventivo municipal o estatal. Dos de los grupos focales se establecieron en Tijuana y uno en Ciudad de México durante el segundo semestre de 2018; cada grupo focal estuvo conformado por cinco personas en promedio. En el grupo de Tijuana participaron dos mujeres. En promedio tenían 10 años en la corporación policial. El grupo de Ciudad de México estuvo conformado por policías que participan en una asociación civil que promueve y se manifiesta por los derechos de los agentes policiales. Los y las participantes pertenecían a la escala básica de la policía. En ambos casos las actividades de los policías y los requerimientos de la corporación influyeron en el número de participantes; sin embargo, hubo consistencia en los datos obtenidos de los tres grupos focales. Dichos grupos focales se integraron fuera de la jornada laboral de los policías.

Las entrevistas semiestructuradas se efectuaron en 2009 como parte de la tesis de maestría del primer autor. A pesar de la distancia temporal de 10 años, se decidió integrar dichas entrevistas, cuyo análisis en el tema de corrupción no se hizo antes, pues se observó consistencia con lo obtenido en los grupos focales; además se consideró que no han ocurrido cambios relevantes en la estructura policial y los procesos internos. Estas entrevistas permitieron ilustrar los discursos de los policías de Ciudad de México y Tijuana. Se entrevistó a 21 policías estatales de Yucatán, asignados a la ciudad de Mérida; tres fueron mujeres; en promedio tenían 10 años trabajando para la corporación y pertenecían a la escala básica de la policía. Las entrevistas se efectuaron durante la jornada laboral de los policías, siendo que el número de participantes estuvo determinado por la saturación de la información. Para garantizar el anonimato de los participantes, durante los grupos focales y entrevistas se omitió mencionar sus nombres; además, en la elaboración de este informe se omiten nombre, edad, procedencia y otros datos que pudieran revelar su identidad.

\section{Materiales}

Para la integración de los grupos focales se utilizó una guía que contenía el objetivo general del estudio y los temas de interés relacionados con sus funciones, las condiciones laborales físicas y sociales de su trabajo, así como los efectos que derivan de dichas condiciones. La corrupción no fue un tema inicial en los grupos focales; pero después se hicieron preguntas al respecto ya que los y las policías sí lo refirieron. Para las entrevistas semiestructuradas se usó una guía de preguntas relacionadas con el ser y quehacer del policía, sus condiciones laborales y los efectos de dichas condiciones, y se incluyó una pregunta general acerca de la corrupción: "¿Qué opinas respecto a la corrupción en la corporación?". A partir de ésta se plantearon otras preguntas para profundizar en el tema.

\section{Procedimiento}

A los policías de Tijuana se les invitó por medio de sus superiores; la mayoría de los que asistieron al primer grupo focal se retiraron. Después se les invitó de manera personal y se solicitó su participación voluntaria durante el horario de clases sabatinas en la Academia Municipal de Policías, con autorización de la Dirección de Policía. Los policías de Ciudad de México acudieron por invitación de oficiales que pertenecen a una organización civil que se manifiesta por los derechos de los policías; la participación se redujo por motivos laborales. Los policías de Yucatán fueron registrados de manera directa, con autorización de altos mandos.

Tanto a los participantes de los grupos focales como a las personas entrevistadas se les explicó la intención académica y de investigación de las sesiones; también se les explicó que la información que proporcionaran se usaría de manera confidencial y que se guardaría el anonimato, y que su participación era libre y voluntaria. Se les solicitó autorización para audiograbar las sesiones, se aclararon sus dudas y se les pidió firmar un documento donde manifestaban haber sido informados de estos aspectos y que aceptaban participar en la investigación. Los autores conservamos en archivo dichos documentos. Como no se hicieron intervenciones que arriesgaran la integridad o la salud de los participantes, se consideran bajos los riesgos potenciales de esta investigación. Aun así, en todo momento se tuvo cuidado respecto al bienestar de la persona y el cumplimiento de los principios éticos de la investigación.

Debido a que la deseabilidad social es un factor que pudo afectar las respuestas de los participantes, los gru- 
pos focales y entrevistas se efectuaron sin la presencia de sus superiores; además se les insistió en el anonimato y confidencialidad con que se utilizaría la información.

\section{Análisis}

Se hizo un análisis de contenido cualitativo, para lo cual se desarrolló una codificación y categorización inductiva (Mayring, 2014); es decir, se generaron códigos a partir del texto, que fueron agrupados en categorías, según su relación. Para la organización del material se utilizó el software Altas.ti versión 8.4 para análisis de datos cualitativos. En el texto se cita parte de los relatos de los policías; dichos relatos se modificaron para hacerlos más comprensibles; por ejemplo, se eliminaron muletillas, regionalismos, sonidos guturales y tartamudeos, pero se procuró conservar su sentido original.

\section{Resultados}

A partir de sus relatos podemos decir que los policías identificaron dos ámbitos donde se efectúan actos de corrupción: 1) dentro de la corporación, y 2) en la interacción policía-ciudadanía. También identificaron factores que favorecen a que se presenten dichos actos en cada uno de esos ámbitos y sus efectos.

\section{Factores que favorecen a la corrupción}

En sus relatos se observó que un factor que favorece a la corrupción dentro de la misma corporación, es el influyentismo. Los oficiales señalaron que la corrupción inicia desde las esferas de mayor poder cuando, por ejemplo, se asignan cargos directivos sin llevar a cabo el proceso de contratación correspondiente debido a las influencias políticas; por lo tanto, los cargos directivos son ocupados por razones ajenas a la carrera policial, como los oficiales desearían.

Antes, para ser jefe de alto nivel era necesario tener cierta antigüedad y haber sido policía de a pie, patrullero o jefe de sección, hasta llegar a ser jefe de sector; ahora no (A. Grupo focal).

Hoy los mandos son personas que por apoyar en la campaña política de una persona les dicen "vete de director o de subdirector [de la policía]". No son de los que empezaron desde abajo; son policías que nunca han patrullado (B. Grupo focal).

Este proceso de obtención de cargos también se observa, según indicaron los oficiales, en los aviadores, es decir, personas registradas en la nómina de la corporación que, a pesar de recibir un sueldo no se presentan a trabajar; esto con el conocimiento de los mandos superiores. Estas situaciones son resultado sobre todo de su relación con algún político o directivo, o a que pagan para poder ausentarse del servicio.

Tenemos compañeros, como normalmente se dice, en el aire, "aviadores"; ésa es una entrada de dinero [para los jefes], otra pues... los que Ilegan a faltar, ésa es otra entrada de dinero para ellos (A. Grupo f

Otro factor que favorece la corrupción dentro de la corporación son algunas prácticas disciplinarias habituales. En los relatos se observó una particular referencia a los arrestos, medida usada ante faltas y violaciones a normas y reglas policiales; sin embargo, los oficiales indicaron que se abusa de esta medida aplicándose con mayor frecuencia que en el pasado, incluso sin que se haya presentado alguna falta. Según el INEGI (2018), durante 2017 a nivel nacional $83.3 \%$ de los policías federales, estatales y municipales refirió como sanción aplicada las llamadas de atención, $78.2 \%$ arrestos y $62.5 \%$ amonestaciones por escrito; siendo que $32.1 \%$ de los policías preventivos estatales y $15.9 \%$ de la policía preventiva municipal recibieron algún tipo de sanción durante 2017. En los relatos de los oficiales se observó que, de los arrestos, de manera directa o indirectamente, los superiores esperan que los oficiales arrestados ofrezcan dinero o algún tipo de servicio o favor a cambio de que no se les aplique dicha medida.

Hoy se abusa de los arrestos; cuando no encuentran algún motivo para arrestarnos indican un artículo de ley que dice que el arresto puede ser por demostrar disgusto o antipatía ante una supervisión. Es una problemática muy grave; los mandos lo usan para doblegar al policía, e incluso como una manera fácil de obtener dinero (A. Grupo focal).

Por otro lado, al hablar de la corrupción que se presenta en la interacción policía-ciudadanía, los factores más relevantes que la propician, según se observó en los relatos de los oficiales, son la normalización y la racionalización. Cabe señalar que, de acuerdo con el INEGI (2018), a nivel nacional, por cada mil elementos de policía de los tres ámbitos, 1,391 recibieron soborno por parte de los ciudadanos durante 2017. Los oficiales describieron la corrupción como una respuesta a un fenómeno normalizado; aceptaron que existe, pero no la reconocieron en primera persona, adjudicando la responsabilidad a los ciudadanos. Consideraron que la corrupción está en todos lados, que siempre ha existido y que por tanto es difícil de erradicar. Tendieron a pensar que son maneras de actuar instauradas en el quehacer del policía y en la sociedad en general; es una práctica normalizada.

No sólo el policía es corrupto; todos los ciudadanos son corruptos. Un maestro, un doctor, to- 
dos son corruptos; simplemente se refleja más en el policía (A. Entrevista).

A uno mismo le pasa; por ejemplo, cuando vas a hacer un trámite y no quieres hacer fila, aunque no seas policía, ofreces dinero para evitarla. Eso es algo normal (C. Grupo focal).

Respecto a la racionalización, se observó que los policías reconocieron la existencia de actos de corrupción en su interacción con la ciudadanía; sin embargo, generaron una serie de explicaciones y justificaciones para la aceptación de dichos actos. Una de las principales razones que argumentaron fue que la corrupción es propiciada por los ciudadanos que ofrecen dinero al oficial a cambio de que no se les aplique la multa o sanción respectiva.

La misma gente lo ocasiona; la gente que comete una infracción o delito lógicamente no quiere pagar multa grande o estar detenido, y te ofrecen algo para solucionarlo; nosotros no lo exigimos a la gente; sería un riesgo para nosotros (B. Entrevista).

La mayoría de las personas tiene doble moral; quieren que se aplique la ley, pero no a ellos. [...] Policías hay buenos y malos, pero la ciudadanía es la que alimenta la corrupción y se va con esa imagen (B. Grupo focal).

Además, en los relatos se observó que las justificaciones de los policías tienen un sentido positivo. Consideraron, por ejemplo, que la ley no debe aplicarse de manera estricta, sino más bien en algunas ocasiones se debe ser flexible. También consideraron que el dinero que les ofrece la gente es un regalo por el buen trato brindado o por haber sido comprensivos. Estas situaciones, al ser mal interpretadas, son percibidas como actos de corrupción.

A veces le dices a un ciudadano "caballero, está cometiendo una falta". Le explico que no lo detuve para pedirle dinero sino para señalarle su error, pero dicen "me gustó su trato; mi deber como ciudadano es agradecerle de alguna manera; le regalo 100 pesos para que compre un refresco". Es un regalo; no se lo pedí; él me lo está dando (C. Entrevista).

Con menor énfasis indicaron que los actos de corupción relacionados con la ciudadanía obedecen a que los sueldos que perciben son bajos. De acuerdo con la Secretaría de Gobernación (2018), hasta el 31 de julio de 2017 el promedio nacional del salario neto de policías preventivos estatales y municipales era de 9,993 pesos al mes (casi 524 dólares). En nueve de 32 entidades federativas los policías preventivos tenían sueldos inferiores a dicha cantidad.
Por otro lado, en los relatos de los oficiales se observó que los arrestos que tienen en la corporación policial como medida disciplinaria, también son un factor que favorece a los actos de corrupción con la ciudadanía. Los policías consideran estos actos de corrupción como necesarios para su economía, sobre todo para recuperar el dinero que usaron para comprar sus alimentos durante el arresto o para pagar a sus superiores para no ser arrestados.

[Algunos compañeros que pagaron por su arresto o que gastaron dinero], en su siguiente turno salen a la calle no con la intención de servir ni proteger; sólo están cazando a la "víctima". Salen con la intención de recuperar ese dinero que tuvieron que desembolsar. Es una cadenita; es realmente eso, una cadenita (A. Grupo focal).

\section{Efectos de la corrupción}

Además de los factores que favorecen a la corrupción, los oficiales refirieron en sus relatos diversas situaciones y condiciones laborales que derivan de manera directa o indirecta de la corrupción; las principales son: 1) existencia de aviadores (personas registradas en la nómina que no se presentan a trabajar, y a pesar de ello reciben un sueldo); 2) equipamiento deficiente e insuficiente, y 3) directivos sin experiencia policial. En los relatos se observó un mayor énfasis en los dos primeros aspectos.

La existencia de aviadores favorece, desde la perspectiva de los participantes, a que no se tenga el personal suficiente, y por tanto a las jornadas laborales extensas. Es necesario indicar que, de acuerdo con la Secretaría de Gobernación (2018), durante 2017 a nivel nacional había 127,689 policías preventivos estatales en activo; sin embargo, al restar 8,556 elementos que no aprobaron las evaluaciones de control de confianza, quedó un total de 119,133 elementos conformando el estado de fuerza real operativo. Por tanto, hay 0.8 policías por cada mil habitantes, siendo que la ONU establece un estándar mínimo de 1.8 policías por cada mil habitantes. Para lograr dicho estándar son necesarios 96,022 elementos nuevos. Al no haber el personal necesario, los oficiales no son relevados o no se les asigna tiempo para descansar.

Esos compañeros que faltan pudieran ser un gran apoyo [...]. Si somos 30, 15 son aviadores y 15 trabajamos; de esos 15, siete no vienen y ocho se quedan a trabajar, y de esos ocho tres o cuatro son el escribiente, el armero y el jefe. Los que quedamos tenemos que hacer el trabajo de los demás [...]. Los aviadores impiden que haya gente que me releve para descansar o sentarme un rato (A. Grupo focal). 
En los relatos de los oficiales se observó una frecuente referencia a las jornadas laborales extensas. Según datos del INEGI (2018), durante 2017 los policías de los tres órdenes a nivel nacional trabajaron en promedio 70 horas a la semana. Los oficiales reconocieron que el sistema de horarios de la corporación, la falta de personal, las necesidades de servicio y otros factores estructurales favorecen a esta situación. Dichas jornadas laborales son más extensas en caso de que hayan sido arrestados.

Desde hace siete años tengo un horario laboral de 24 horas por 48 de descanso [...]. No siempre son esas 24 horas de trabajo; por supuestas necesidades del servicio que alegan los mandos, trabajamos otras 12 horas. Hace casi tres años, debido a movimientos sociales que se dieron en la ciudad, trabajamos en promedio 48 horas continuas por menos de 24 de descanso (A. Grupo focal).

Otro efecto importante que se identificó en los relatos de los participantes, es que el equipamiento con que cuenta la corporación es deficiente e insuficiente. Como indicaron algunos oficiales, varias armas no se están en condiciones adecuadas; lo mismo ocurre con los escudos, visores de los cascos y chalecos antibalas; las patrullas y demás vehículos de uso policial no son suficientes y en ocasiones no se les proporciona el mantenimiento adecuado.

En días festivos, que trabajamos más elementos, no hay armas suficientes. Hay zonas que están peor; en ocasiones no tienen patrullas para salir, no hay armas ni radio. [...] La corporación me dio un uniforme, una placa y un cinto de fornitura. Me han dado cuatro uniformes y llevo cinco años trabajando, dos o tres pares de botas y una cachucha. Todo lo demás hay que comprarlo (B. Grupo focal).

Según los relatos de los oficiales, esto repercute sobre todo de dos maneras; una es la dificultad para el cumplimiento de sus funciones. Las actividades de vigilancia, las detenciones y resguardo de personas, entre otras, se ven afectadas. Los visores de cascos y escudos rallados dificultan la visión, y por tanto colocan en desventaja al policía; las armas y chalecos antibalas en condiciones inadecuadas no dan confianza y seguridad al policía en las intervenciones. Un ejemplo de esto es lo que refirieron oficiales asignados a zonas altas de la ciudad.

El clima donde estoy es muy extremo; son climas bajo cero. El equipo que nos dan no es térmico; por lo tanto, uno tiene que usar mallas térmicas, doble o hasta triple calcetín, un pants de algodón, el pantalón, dos playeras, una sudadera, y si se puede otra sudadera, y la chamarra. Luego el chaleco, guantes y un tipo de bufanda. Todo esto nos quita mucha movilidad, nos estorba, nos impide movernos adecuadamente (A. Grupo focal).

Debido a estas circunstancias los policías se ven en la necesidad de comprar sus accesorios, e incluso de comprar las balas que utilizan. Esto, según refirieron, afecta su economía (19 pesos equivalen a un dólar).

Tenemos que comprar todo; yo he invertido poco, como 5,000 pesos. Una lámpara buena cuesta como 250 pesos, la placa 200, las insignias 200, la funda para pistola 600, las esposas como 800 y de nivel más bajo. La Secretaría te da, por ejemplo, fundas desechables que en un forcejeo te pueden quitar el arma. Entonces tienes que invertirle (A. Grupo focal).

Según el INEGI (2018), a nivel nacional $86.4 \%$ de los policías estatales y municipales con funciones operativas obtuvo por su cuenta al menos un accesorio o material de apoyo o protección; esto se debió a que no se lo proporcionó la institución, no fue proporcionado en cantidad suficiente o no es adecuado para el cumplimiento de sus funciones. El $2.2 \%$ de la policía preventiva estatal y $6.7 \%$ de la policía preventiva municipal obtuvo por su propia cuenta armas, municiones o accesorios para armamento para el cumplimiento de sus funciones.

\section{DisCusión}

La corrupción genera una serie de efectos que dañan a la sociedad (instituciones y personas que la conforman). Los policías refirieron efectos en la corporación y en sí mismos, entre ellos la existencia de aviadores, que favorece a que las jornadas laborales sean extensas; y la deficiencia o inexistencia del equipamiento, que impacta en el cumplimiento de sus funciones y en su economía. En ambos casos se observan efectos en la corporación que también afectan a los oficiales, a lo que se suman efectos directos de la corrupción, como cuando les piden dinero para no ser arrestados.

Las y los policías preventivos desempeñan diversas funciones en escenarios y espacios también diversos; debido a esto, la interacción policías-ciudadanía se evidencia en numerosas modalidades. Si a esto se suman factores como una estructura jerárquica y una cultura policial que favorece y promueve actos de corrupción, bajos sueldos y uso de sus propios recursos económicos para comprar equipamiento que la corporación proporciona en mal estado, o no proporciona; interés por parte de los ciudadanos por evitar pagar multas o evitar trámites burocráticos complejos, entre otros, podemos pensar 
que se tiene una suma de factores que favorecen de manera relevante a los actos de corrupción. Como indican Alvarado y Silva (2011), la diversidad de interacciones y espacios en que el policía desarrolla sus funciones hacen difícil su vigilancia, a la vez que se torna un campo propicio para actos de corrupción.

Ahora bien, de acuerdo con sus relatos, se puede decir que los policías identificaron dos escenarios donde se desarrollan actos de corrupción en el ámbito policial: en la corporación y en la interacción policías-ciudadanía, lo cual coincide con lo reportado por el INEGI (2018). En estos ámbitos, los tipos de corrupción que se identificaron siguiendo la propuesta de Punch et al. (apud Newburn, 1999): corrupción de autoridad, al momento de recibir ganancias por ser una figura de autoridad en la sociedad; kickbacks o soborno, al recibir ganancias de particulares sea como pagos para que no les aplique la ley o como agradecimiento por su servicio como policías, y los pagos internos, sobre todo por los "aviadores" y por oficiales que quieren evitar el cumplimiento de su arresto. Es necesario mencionar el nepotismo, que se presenta cuando otorgan puestos de directivos a familiares, por amistad o por relaciones políticas.

También se identificó la búsqueda tanto de beneficios negros como blancos (López-Alvarado, 2007). Los beneficios negros hacen referencia al dinero que reciben los policías para no aplicar la ley, sea porque el ciudadano lo ofrece o porque es solicitado por el oficial. Llama la atención que los oficiales tendieron a justificar estos actos argumentando que ellos no solicitan dinero, sino más bien la población, con tal de evitar el pago de multas altas o los trámites engorrosos, prefieren dar el dinero; o también argumentando que la aplicación de la ley debe ser flexible, lo que en ocasiones conlleva que los ciudadanos les den dinero como agradecimiento. Los beneficios blancos se refiere a recibir compensaciones monetarias o en producto, como propinas o como muestra de agradecimiento, por el servicio del policía. Como también indica la literatura, este tipo de actos los policías no los consideran corrupción porque argumentan que ellos no lo solicitan; que más bien es una manera en que la ciudadanía muestra su agradecimiento por el buen servicio. En ambos tipos de beneficios los policías tendieron a racionalizar y justificar la corrupción.

Si se quiere erradicar la corrupción en el ámbito policial, es necesario comprender los factores que la promueven. De acuerdo con los relatos de los policías, la corrupción que se presenta en la corporación obedece al influyentismo y a los arrestos disciplinarios arbitrarios que, si bien son en sí actos de corrupción, favorecen a que tengan lugar otros actos de corrupción.
El influyentismo hace referencia a un fenómeno cultural normalizado en la sociedad mexicana, pero que no es exclusivo de ésta; un fenómeno responsable de la asignación de puestos en sectores privados y públicos. Así, en la interacción policías-ciudadanía los factores que identificaron los policías fueron la normalización, la racionalización y los sueldos bajos.

Abordar este fenómeno desde el construccionismo social permitió conocer los significados que los policías han construido en torno a la corrupción. Observamos y mantenemos como hipótesis para análisis posteriores que uno de los principales factores que propician y mantienen la corrupción son los significados que se han establecido al respecto. Esto cobra importancia si se considera que los significados que construimos se pueden institucionalizar, debilitando o significando como inaceptable otras versiones (Carrillo, 2006). De ahí que pueda ocurrir que los comportamientos corruptos sean mejor vistos que las conductas no corruptas. Si bien los policías hicieron una diferencia entre la corrupción que se presenta en la corporación y la que se presenta en la interacción policía-ciudadano, en ambos casos se identificaron significados que, según sus narraciones, favorecen a que estos actos se mantengan arraigados.

Por un lado, observamos que los policías incluyeron en sus significados de corrupción que es promovida y permitida por los altos mandos, ya sea para ocupar cargos o para conseguir dinero por medio de los arrestos; esto favorece a la instauración de la corrupción como algo propio de la corporación, incluso que la corrupción tenga lugar y venga desde los altos mandos tiende a legitimar dichos actos. Por otro lado, normalizar y justificar la corrupción que se da en la interacción policía-ciudadano favorece a que se continúe con estos actos y que incluso nuevos elementos se involucren en ellos. Es necesario considerar que los significados y lo que las personas narran de sus experiencias y su entorno, se construyen y reproducen en contextos interaccionales, culturales, históricos, institucionales y discursivos, entre otros (Riessman, 2008).

En este sentido la corrupción en el ámbito policial, o en cualquier otro, no surge de manera espontánea sino que está retroalimentada y sostenida por su contexto. La comprensión que cada persona tiene de sí mismo y del mundo está en función de los relatos a que tiene acceso y con que interactúa (Rivas, 2010). Tal como observamos en el caso de los policías, los discursos que se tienen en la corporación, en todos los niveles, tienden a aceptarla y promoverla. Independientemente de las condiciones laborales y estructurales de la corporación, consideramos de relevancia deconstruir las narrativas mantenidas entre los policías 
porque, como se indicó, los significados construidos favorecen a que se generen algunas líneas de acción.

Por otro lado, los policías refirieron diferentes efectos de la corrupción; sobre todo hicieron referencia a efectos en sus condiciones laborales. La labor que desarrollan los policías implica que están en condiciones físicas y psicológicas óptimas. Sin embargo, como los policías refirieron, no tienen el equipamiento adecuado, trabajan horarios muy largos y los sueldos son bajos, entre otras condiciones que ponen en riesgo su salud y su vida. Si no se mejoran de modo sustancial las condiciones en que los/las policías desempeñan sus funciones, pocos avances podrán verse en materia de seguridad pública (Suárez de Garay, 2008).

Los bajos salarios pueden ser objeto de conflictos. Zepeda (2010) indica que ser policía en México implica un alto riesgo, un sueldo bajo y un estigma social muy negativo. Los salarios de los policías pueden causar situaciones de discriminación, privación y conflicto. Desde el punto de vista económico, los bajos salarios pueden ser una variable o potencial causa para la corrupción de las policías (Hyemin, Valencia, Rodríguez, Preciado y Soltero, 2013). Lo observado en los relatos de los policías apoya esta idea; sin embargo, consideramos que independientemente de ello se debe favorecer la deconstrucción de las narrativas que favorecen la corrupción en la corporación. De no trabajarse en ellas podrían continuar los actos de corrupción, a pesar de que se incrementen los sueldos.

\section{Conclusiones}

En sus diferentes formas y alcances, la corrupción es un fenómeno social que en México afecta a diferentes instituciones y a la sociedad en general. Para intervenir sobre la corrupción es necesario el entendimiento de todos los aspectos que la conforman y la promueven; no obstante, dicha tarea es compleja porque surge de diversos factores relacionados con la cultura y la sociedad en general, pero también de factores específicos de cada grupo o institución. Por lo regular, los estudios al respecto han abordado aspectos estructurales y sociales, dejando de lado la perspectiva de las personas involucradas. Es por ello que en este estudio abordamos el fenómeno desde la perspectiva de los policías, permitiéndonos observar que, desde su enfoque, la corrupción abarca tanto a los mandos altos de la corporación como a los policías de rangos bajos, dentro y fuera de la corporación, y que en cada uno de esos escenarios la corrupción adopta determinadas modalidades, afectando a la corporación como tal, pero también a ellos como individuos.
Los policías desarrollan una profesión de alta responsabilidad que además genera altas expectativas en la sociedad; al mismo tiempo que debe satisfacer el servicio de los clientes, debe cumplir y hacer cumplir la ley (Castro, Orjuela, Lozano, Avedaño y Vargas, 2011). Para cumplir con ello, es necesario tener condiciones laborales óptimas, que no se alcanzarán mientras la corrupción siga instaurada en las corporaciones policiales. Es preciso indicar que la corrupción también favorece la desconfianza hacia las corporaciones policiales (Grijalva y Fernández, 2017).

Una de las estrategias que recomendaríamos seguir es la deconstrucción de significados que favorecen a dichos actos. Los significados construidos pueden ser reconstruidos para favorecer la reducción de estos actos; a fin de cuentas, las interpretaciones y sentidos que damos a la realidad no son las únicas posibles ni son inamovibles; las personas podemos generar gran cantidad de realidades (Crespo, 2003) por medio de la construcción y reconstrucción de significados.

Dentro de las limitaciones de este estudio encontramos la poca disponibilidad de los policías para los grupos focales, como consecuencia de sus necesidades laborales o a que se les reunió después de su jornada laboral, lo que implicó que estuvieran cansados. Se sugiere, para futuras ocasiones, acordar un mejor horario para su participación. Otra limitante es que se recurrió a policías que pertenecen a una organización que promueve y defiende los derechos de los policías; esto pudo haber favorecido a que se tuvieran respuestas sesgadas; sin embargo, se observó consistencia de sus respuestas con los otros grupos focales, con las entrevistas y con la literatura. Es una población en la que la deseabilidad social y el temor a los superiores puede influir en la información que proporcionan acerca de su medio laboral; en este caso se trató de aminorar la influencia de estos dos factores, incluyendo sólo a oficiales de la escala básica y asegurando el anonimato y la confidencialidad de la información.

\section{Referencias}

Alvarado Mendoza, A., \& Silva Forné, C. (2011). Relaciones de autoridad y abuso policial en la Ciudad de México, Revista Mexicana de Sociología, 73(3), 445-473.

Asch, B., Fu, M., \& Burger, N. (2011). Chapter four. Empirical data on corruption and inputs to professionalism in the Mexican Security Services en Mitigating Corruption in Government Security Forces: The role of Institutions, Incentives and Personnel Management in México. Rand Corporation eBook Academic Collection (EBSCOhost).

Carrillo, L. (2006). La (lógica) construcción de la realidad. Ámbitos (15), 129-156. 
Castro, Y., Orjuela, M., Lozano, C., Avedaño, B., \& Vargas, N. (2011). Estado de salud de una muestra de policías y su relación con variables policiales. Diversitas: Perspectivas en Psicología, 8(1), 53-71.

Crespo, E. (2003). El construccionismo y la cognición social: metáforas de la mente. Psicología y Sociedad, 40(001), 15-26.

Donoso, T. (2004). Construccionismo social: aplicación del grupo de discusión en praxis de equipo reflexivo en la investigación científica. Revista de Psicología, 13(001), 9-20.

Ema, J., García, S., \& Sandoval, J. (2003). Fijaciones políticas y trasfondo de la acción: Movimientos dentro/fuera del socioconstruccionismo. Política y Sociedad, 40(001), 71-86.

Fink, H., \& Boehm, F. (2011). Corrupción en la policía de tránsito. Una primera aproximación a través de entrevistas con taxistas. Relaciones. Estudios de historia y sociedad, 32(126), 67-85. Recuperado de http://www.redalyc.org/ articulo.oa?id $=13718501003$

Gergen, K., \& Warhus, L. (2001). La terapia como construcción social: Dimensiones, deliberaciones y divergencias. Sistemas Familiares, 17(001), 11-27.

Grijalva Eternod, Á. E., \& Fernández Molina, E. (2017). Efectos de la corrupción y desconfianza en la policía sobre el miedo al delito. Un estudio exploratorio en México. Revista Mexicana de Ciencias Políticas y Sociales (231), 167-198.

Guanaes, C., \& Rasera, E. (2006). Therapy as social construction: an interview with Sheila McNamee. Revista Interamericana de Psicología, 40(001), 127-136.

Hernández Aguilar, S. A. (2017). La corrupción y los grupos de poder en México. Revista Internacional Transparencia e Integridad (4).

Hernández-Sampieri, R., \& Mendoza Torres, C. (2018). Metodología de la investigación. Las rutas cuantitativa, cualitativa y mixta. México: McGraw-Hill.

Hyemin, J., Valencia, S., Rodríguez, C., Preciado, L., \& Soltero, R. (2013). Ambiente laboral violento y salud mental en los policías del a zona metropolitana de Guadalajara. Waxapa, 1(8), 31-48.

Instituto Nacional de Estadística y Geografía (INEGI) (2018). Primera Encuesta Nacional de Estándares y Capacitación Profesional Policial (Enecap). Comunicado de prensa número 548/18. Recuperado de https://www.inegi.org. mx/contenidos/saladeprensa/boletines/2018/EstSegPub/ ENECAP2017.pdf

López Alvarado, M. (2007). Corrupción y control en la organización policial preventiva. Acta Republicana Política y Sociedad, año 6 (6), 47-56

Martínez Miguélez, M. (2015). Ciencia y Arte en la Metodología Cualitativa. (2a. ed.). México: Trillas.
Mayring, P. (2014). Qualitative content analysis: Theoretical foundation, basic procedures and software solution. Klagenfurt: Gesis. Recuperado de http://www.ssoar. info/ssoar/bitstream/handle/document/39517/ssoar2014-mayring-Qualitative_content_analysis_theoretical_ foundation.pdf?sequence $=1$

Newburn, T. (1999). Understanding and preventing police corruption: lessons from the literature. London: Research, Development, and Statistics Directorate.

Orces, D. (2017). Victimización por corrupción por la policía. Revista de Ciencia Política (Santiago), 28 (2), 203-208.

Perdomo, M. (2002). Socioconstruccionismo y cultura. Relaciones, lenguaje y construcción cultural. Recuperado de http://bibliotecadigital.icesi.edu.co/biblioteca digital/bitstream/item/3767/1/Socioconstruccionismo_ cultura 2002.pdf

Riessman, C. (2008). Narrative methods for the human sciences. Thousand Oaks, California: Sage.

Rivas, J. (2010). Narración, conocimiento y realidad. un cambio de argumento en la investigación educativa. En J. Rivas y D. Herrera (coords.), Voz y educación. La narrativa como enfoque de interpretación de la realidad (pp.17-36). Barcelona: Octaedro.

Sandoval, J. (2010). Construccionismo, conocimiento y realidad: Una lectura crítica desde la psicología social. Revista Madrid, septiembre (23), 31-37.

Secretaría de Gobernación (Segob) (2018). Modelo óptimo de la función policial. Diagnóstico nacional sobre las policías preventivas de las entidades federativas. Gobierno de los Estados Unidos Mexicanos. Recuperado de https:// www.gob.mx/sesnsp/es/articulos/modelo-optimo-de-lafuncion-policial-172616?idiom=es

Silva, C. (2016). The excessive use of force by Mexico City law enforcement agencies: Corruption, normal abuse and other motives. Mexican Law Review, IX (1), 3-21.

Suárez de Garay, M. E. (2008). Los policías: Una averiguación antropológica. México: ITESO/Universidad de Guadalajara.

Transparency International (2018). Corruption Perception Index 2018. Transparency International. Recuperado de https:// www.transparency.org/cpi2018

Valverde, C. (2009). Los pacientes sangran historias: Un enfoque narrativo para disminuir los desencuentros clínicos. Norte de Salud Mental, 8 (34), 75-84.

Zepeda L., G. (2010). La policía mexicana dentro del proceso de reforma del sistema penal. México: CIDAC. 


\section{Meta-Análisis del Artículo}




\section{Dimensión Cuantitativa}

\section{Perfil de Evaluación entre pares}
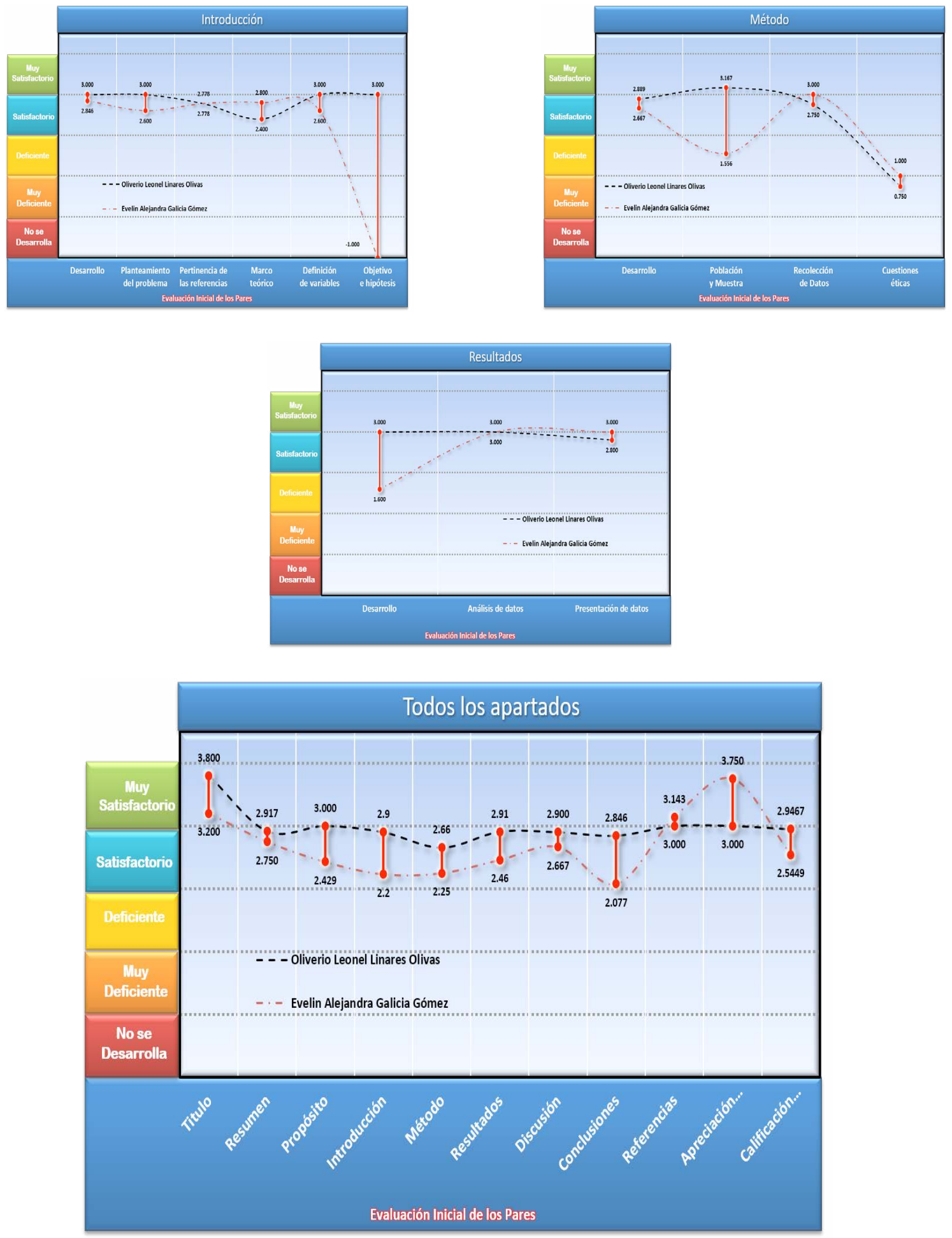


\section{Índice de Concordancia}

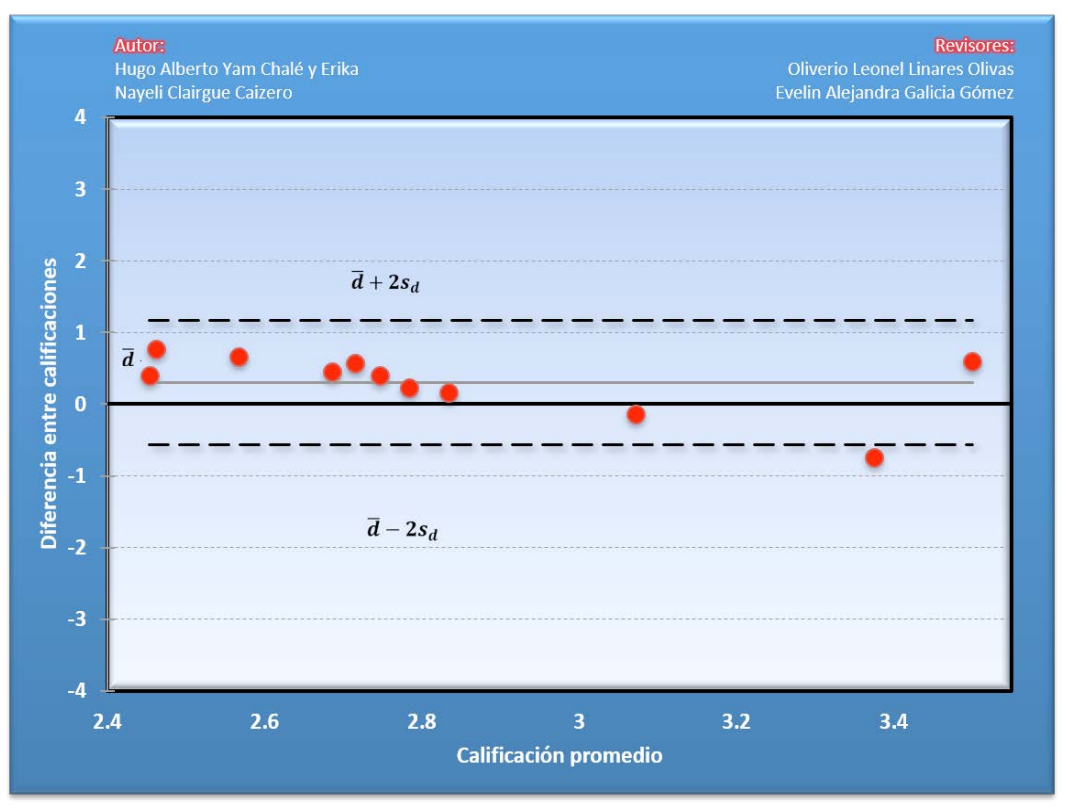

\section{Índice de Acuerdo}

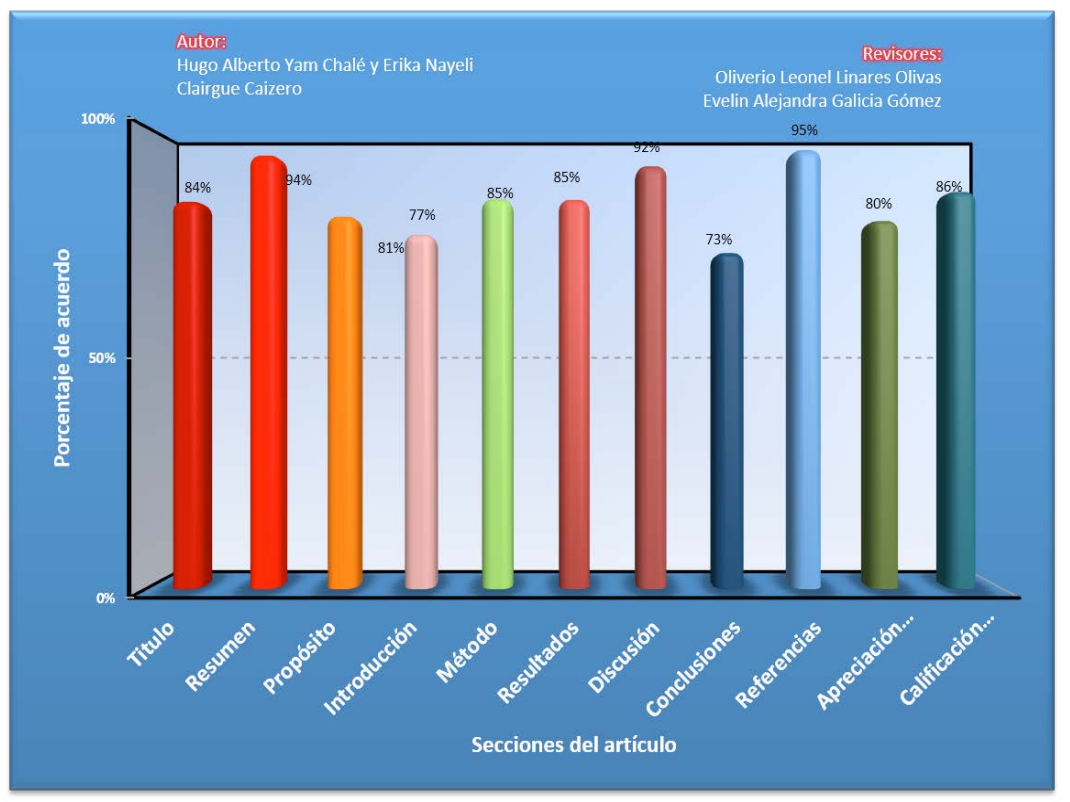


Dimensión Cualitativa

\begin{tabular}{|c|c|}
\hline Revisor 1 & Revisor 2 \\
\hline Oliverio Leonel Linares Olivas & Evelin Alejandra Galicia Gómez \\
\hline \multicolumn{2}{|c|}{ Título/Autoría } \\
\hline Ninguno & $\begin{array}{l}\text { En el título original es general "...por policías preventivos } \\
\text { de México", aunque el estudio en algunos estados, al leerlo } \\
\text { se entiende que es en toda la república y no en estados } \\
\text { específicos. }\end{array}$ \\
\hline \multicolumn{2}{|c|}{ Resumen } \\
\hline El resumen rebasa el número de palabras. & $\begin{array}{l}\text { Deben ser un poco más específicos en mencionar resulta- } \\
\text { dos y conclusiones. }\end{array}$ \\
\hline \multicolumn{2}{|c|}{ Próposito del Estudio } \\
\hline & $\begin{array}{l}\text { Los resultados no están muy bien especificados ya que } \\
\text { no hay un cuestionario o entrevista como anexo que res- } \\
\text { palde que el propósito se haya cumplido }\end{array}$ \\
\hline \multicolumn{2}{|c|}{ Introducción } \\
\hline $\begin{array}{l}\text { Es muy deseable que el marco teórico sea mejorado en } \\
\text { función de las teorías que abordan el fenómeno de la co- } \\
\text { rrupción. El articulo presenta un marco teórico descrip- } \\
\text { tivo solamente. Con una discusión teórica se podrían } \\
\text { mejorar el análisis de resultados y las conclusiones. }\end{array}$ & No hay una sección con objetivos generales o específicos \\
\hline
\end{tabular}




\begin{tabular}{|c|c|}
\hline Revisor 1 & Revisor 2 \\
\hline \multicolumn{2}{|c|}{ Método } \\
\hline $\begin{array}{l}\text { No se justifica el hecho te haber retomado } 21 \text { entrevis- } \\
\text { tas hechas con antelación, es necesario indicarlo. Por } \\
\text { otro lado, el hecho que que hayan pasado } 10 \text { años desde } \\
\text { ese muestreo pone en riesgo la vigencia de la informa- } \\
\text { ción. Sobre todo, en un contexto como es el mexicano, } \\
\text { en donde han existido múltiples cambios en la política } \\
\text { de seguridad nacional. Mi recomendación es que solo } \\
\text { se usen los grupos focales y se les dé más énfasis a su } \\
\text { análisis. Hace falta una sección de consideraciones éti- } \\
\text { cas y acontar cómo es que se controló la desestabilizad } \\
\text { social en un contexto donde los participantes son pre- } \\
\text { cisamente vigilados. }\end{array}$ & $\begin{array}{l}\text { No hay una descripción precisa de de riesgos potenciales } \\
\text { o un consentimiento informado firmado por los partici- } \\
\text { pantes del estudio }\end{array}$ \\
\hline \multicolumn{2}{|c|}{ Resultados } \\
\hline & $\begin{array}{l}\text { Con las preguntas de la entrevista se puede confirmar si } \\
\text { los objetivos esperados fueron cumplidos }\end{array}$ \\
\hline \multicolumn{2}{|c|}{ Discusión } \\
\hline $\begin{array}{l}\text { La discusión es limitada y esto puede deberse a que en } \\
\text { el marco teórico hacen falta argumentos teóricos que } \\
\text { permitan una reflexión más fluida. }\end{array}$ & $\begin{array}{l}\text { Falta que se mencionen las limitaciones y alcances de esta } \\
\text { investigación }\end{array}$ \\
\hline \multicolumn{2}{|c|}{ Conclusiones } \\
\hline $\begin{array}{l}\text { Las conclusiones tienen repercusiones muy importan- } \\
\text { tes, por ello, es deseable que los autores hagan énfasis } \\
\text { en la importancia de un estudio tan relevante para la } \\
\text { seguridad pública. }\end{array}$ & $\begin{array}{l}\text { No hay propuestas dentro de la conclusión o bien como } \\
\text { estas construcciones pueden beneficiar en el problema de } \\
\text { investigación que es la corrupción policial }\end{array}$ \\
\hline \multicolumn{2}{|c|}{ Referencias } \\
\hline $\begin{array}{l}\text { Es deseable revisar la redacción. Puede ser que haya } \\
\text { abuso del punto y la coma, sobre todo en oraciones } \\
\text { donde no existe verbo callado. }\end{array}$ & Faltan referencias más actuales \\
\hline
\end{tabular}




\section{Historia del Proceso}

\section{EDITORIAL}

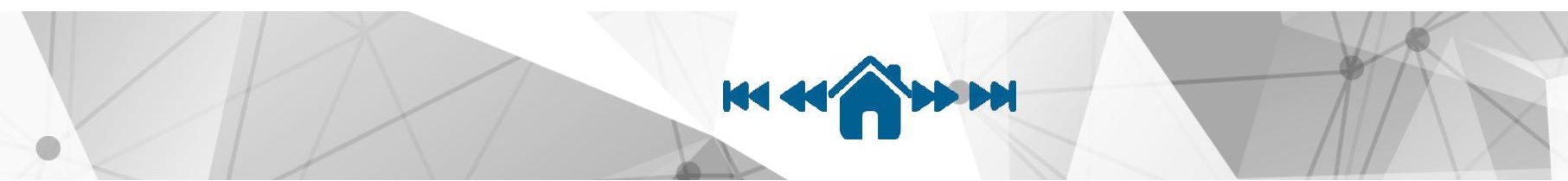

